\title{
The Effect of Different Artificial Soil on Urban Non-Point Source Pollution Reduction in the Artificial Rapid Infiltration System
}

\author{
Junfeng Wu1, Langrun Song2,3, Qian Feng',3, Jingyang Luo ${ }^{2,3}$, Zhaoxia Xue ${ }^{2,3^{*}}$ \\ ${ }^{1}$ Academy of Environmental Planning \& Design Co. Ltd., Nanjing University, Nanjing, China \\ ${ }^{2}$ Key Laboratory of Integrated Regulation and Resource Development on Shallow Lakes, Ministry of Education, Hohai University, \\ Nanjing, China \\ ${ }^{3}$ College of Environment, Hohai University, Nanjing, China \\ Email: *xzhx223@163.com
}

How to cite this paper: $\mathrm{Wu}, \mathrm{J}$. F., Song, $\mathrm{L}$. R., Feng, Q., Luo, J. Y., \& Xue, Z. X. (2018). The Effect of Different Artificial Soil on Urban Non-Point Source Pollution Reduction in the Artificial Rapid Infiltration System. Journal of Geoscience and Environment Protection, 6, 67-76. https://doi.org/10.4236/gep.2018.611005

Received: October 6, 2018

Accepted: November 13, 2018

Published: November 16, 2018

Copyright $\odot 2018$ by authors and Scientific Research Publishing Inc. This work is licensed under the Creative Commons Attribution International License (CC BY 4.0).

http://creativecommons.org/licenses/by/4.0/

\begin{abstract}
The non-point source pollution posed great risks to the urban water environment which has aroused great concerns. Artificial rapid infiltration systems have been widely used in sewage treatment, which have great environmental and economic values. This study investigated the potential of utilizing artificial rapid infiltration systems on the reduction of urban non-point source pollution. The obtained results showed that the components and composition of artificial soils were vital to the operational performance. The mixture of natural soil, coarse sand and zeolite was ideal for the construction of artificial soils. The permeability coefficient of soils could be improved to $0.166 \mathrm{~cm} / \mathrm{min}$ at the optimized ratio of 1:1:0.05 (natural soil, coarse sand and zeolite). Also, high removal efficiency for the typical pollutants in rain runoffs (i.e. COD, $\mathrm{NH}_{4}^{+}-\mathrm{N}, \mathrm{TN}$ and TP) could be simultaneous obtained which was above $74 \%$ in the artificial rapid infiltration systems. The results demonstrated the effectiveness on the reduction of urban non-point pollution by optimized artificial rapid infiltration system.
\end{abstract}

\section{Keywords}

Non-Point Source Pollution, Artificial Rapid Infiltration System,

Permeability Coefficient, Zeolite, Pollutants, Removal Efficiency

\section{Introduction}

The pollution sources of urban water environment are mainly classified into point source pollution (derived from industrial and domestic wastewater) and 
non-point source pollution. Currently, the industrial and domestic wastewater is commonly directly discharged into wastewater treatment plants (WWTPs). Therefore, the point source pollution has been effectively controlled. The non-point source pollution is becoming the key problem in addressing the issue of urban water environment. The non-point source is a dispersed pollution in urban area caused by rainfall runoffs. The contaminants are mainly consisted of organics, eutrophication substances (nitrogen and phosphorus) and suspended solids (Li et al., 2017; Zhuang et al., 2015; Huang et al., 2010). They would enter into surface water and groundwater from atmosphere, grounds and soils through leaching and scouring and ultimately cause serious water environment pollution (Qin et al., 2016). In China, the urban area is densely populated with anthropogenic activities while most of surface is impermeable. The non-point pollution caused by rainfalls is more severe. For example, Jing et al. found that the concentrations of total nitrogen and total phosphorus in storm pipelines of Beijing were respectively 3.2 and 25-folds higher than that of the natural rainfalls (Jing et al., 2013). Moreover, the natural environments and rainfall processes are varied in different cities. In Beijing, the concentrations of suspended solids, chemical oxygen demand, total phosphorus and total nitrogen were respectively 3.9, 13.6, 3.3 and 16-folds higher than that of the V class of Environmental Quality Standard for Surface Water. However, they were respectively 1.7, 8.4, 1.4 and 3.9 folds in Shanghai, correspondingly (Li et al., 2006; Ding \& Liu, 2011). Therefore, the urban non-point source pollution is characteristic of high intensity and wide space-time variation which make its effective control quite difficult (Qin et al., 2016; Huang \& Xiang, 2014; Coppola et al., 2014).

Currently, the main measures taken for urban non-point source pollution control are through vegetation, percolation, wetland retention systems, and so on (Feng et al., 2016; Li et al., 2018; Lai et al., 2016). However, the application of these strategies was frequently restricted by the availability of lands, risks of ecological and environmental pollution, and the high costs of maintenance and management. Therefore, they are usually applied as auxiliary measures rather than the key control measures to control urban non-point source pollution.

The natural soils have the ability of physical retention, chemical precipitation, physicochemical adsorption and exchange due to the specific composition and properties of soil minerals. Moreover, they also provide necessary habitats for various microorganisms. It seems to be a good alternative to effectively and economically decompose and purify the organic and inorganic substances in the wastewater (Liu et al., 2018). However, the suitable permeability and high biological activity (commonly correlated with the soil fertility) were required for the efficient pollutants removal by soil treatment which was hard to meet simultaneously in natural environments. Artificial interference is usually necessary to make the natural soil be an ideal medium for sewage treatment.

The artificial rapid filtration systems mainly enhance the treatment efficiency of wastewater by improving the physical properties of original natural soils (i.e. 
permeability) (Huang, 2005). The basic principles for constructing artificial rapid filtration systems mainly follow three aspects: 1) good permeability 2) high treatment efficiency, and 3) low costs. The typical strategies to improve the permeability of natural soil were accomplished by the addition of coarse sand, zeolite and so on (Wang \& Wang, 2011). Among them, zeolite has been reported to improve the permeability of soil effectively and simultaneously remove ammonia nitrogen, heavy metals and organic pollutants (Boostani et al., 2017; Aljerf, 2018; Wang et al., 2018). For example, the results obtained by Rozic (Roz'ć et al., 2000) show that the adsorption capacity of zeolite for ammonia nitrogen was about 2 times higher than that of clay. Xue et al. also confirmed the positive effects of artificial wetland systems amended with zeolite on ammonia nitrogen removal. The average removal efficiency of ammonia nitrogen in rainstorm water was up to $85 \%$ which could reduce the runoff pollution with short residence time (Xue et al., 2003).

Therefore, the main aim of this study is to investigate the performance of artificial rapid filtration systems on the reduction of urban non-point source in Suzhou optimizing the composition and characteristics of organic soils with different additives. Moreover, the main mechanisms for its promotion on pollutants removal are also explored.

\section{Materials and Methods}

\subsection{Materials}

The soils and coarse sand was obtained in the local regions of Suzhou, Jiangsu, China. The zeolites used in this study are synthetic 13X4A zeolites. The main characteristics are as follows: specific surface area: $200-300 \mathrm{~m}^{2} / \mathrm{g}, K^{+}$exchange capacity: $420 \mathrm{mg} / \mathrm{g}$, adsorption capacity for $\mathrm{H}_{2} \mathrm{O}: 20 \mathrm{~g} / 100 \mathrm{~g}$, specific gravity: $2.6 \%$, crushing strength: $50-60 \mathrm{n} /$ particle, bulk density: $0.8-0.9 \mathrm{~g} / \mathrm{cm}^{3}$ and the particle diameter: $1.5-1.8 \mathrm{~mm}$.

According to the previous monitoring results of surface runoff water in Suzhou, the main pollutants are organic pollutants, eutrophication substances and suspended solids (Huang, 2005). Therefore, the concentrations of chemical oxygen demand (COD), total phosphorus (TP), total nitrogen (TN) and ammonia nitrogen $\left(\mathrm{NH}_{4}^{+}-\mathrm{N}\right)$ were set as the main indices. The wastewater is synthetic to simulate the natural surface runoffs in Suzhou and the main characteristics are shown in Table 1.

\subsection{Correlations of Soil Compositions with the Performance of Artificial Rapid Infiltration System}

The natural soil, coarse sand and zeolite were mixed well with different mixing ratios (shown in Table 2) and then filled into the polymethyl methacrylate (PMMA) soil columns.

The PMMA soil column was shown as Figure 1. The inner diameter of plexiglass soil column is $10 \mathrm{~cm}$ and the thickness of soil layer is $30 \mathrm{~cm}$. The experiment 
Table 1. Characteristics of synthetic runoffs.

\begin{tabular}{ccccc}
\hline Pollutants & COD & TP & TN & $\mathrm{NH}_{4}^{+}-\mathrm{N}$ \\
\hline Concentration $(\mathrm{mg} / \mathrm{L})$ & $500 \pm 10$ & $1 \pm 0.02$ & $20 \pm 2$ & $5 \pm 0.4$
\end{tabular}

Table 2. Characteristics of artificial soils with different mixing ratios.

\begin{tabular}{|c|c|c|c|c|}
\hline Zeolite & $1: 4$ & $1: 3$ & $1: 2$ & $1: 1$ \\
\hline $5 \%$ & $1 \#$ & 5\# & 9\# & 13\# \\
\hline $10 \%$ & $2 \#$ & $6 \#$ & $10 \#$ & 14\# \\
\hline $15 \%$ & $3 \#$ & 7\# & $11 \#$ & $15 \#$ \\
\hline $20 \%$ & $4 \#$ & 8\# & $12 \#$ & $16 \#$ \\
\hline
\end{tabular}

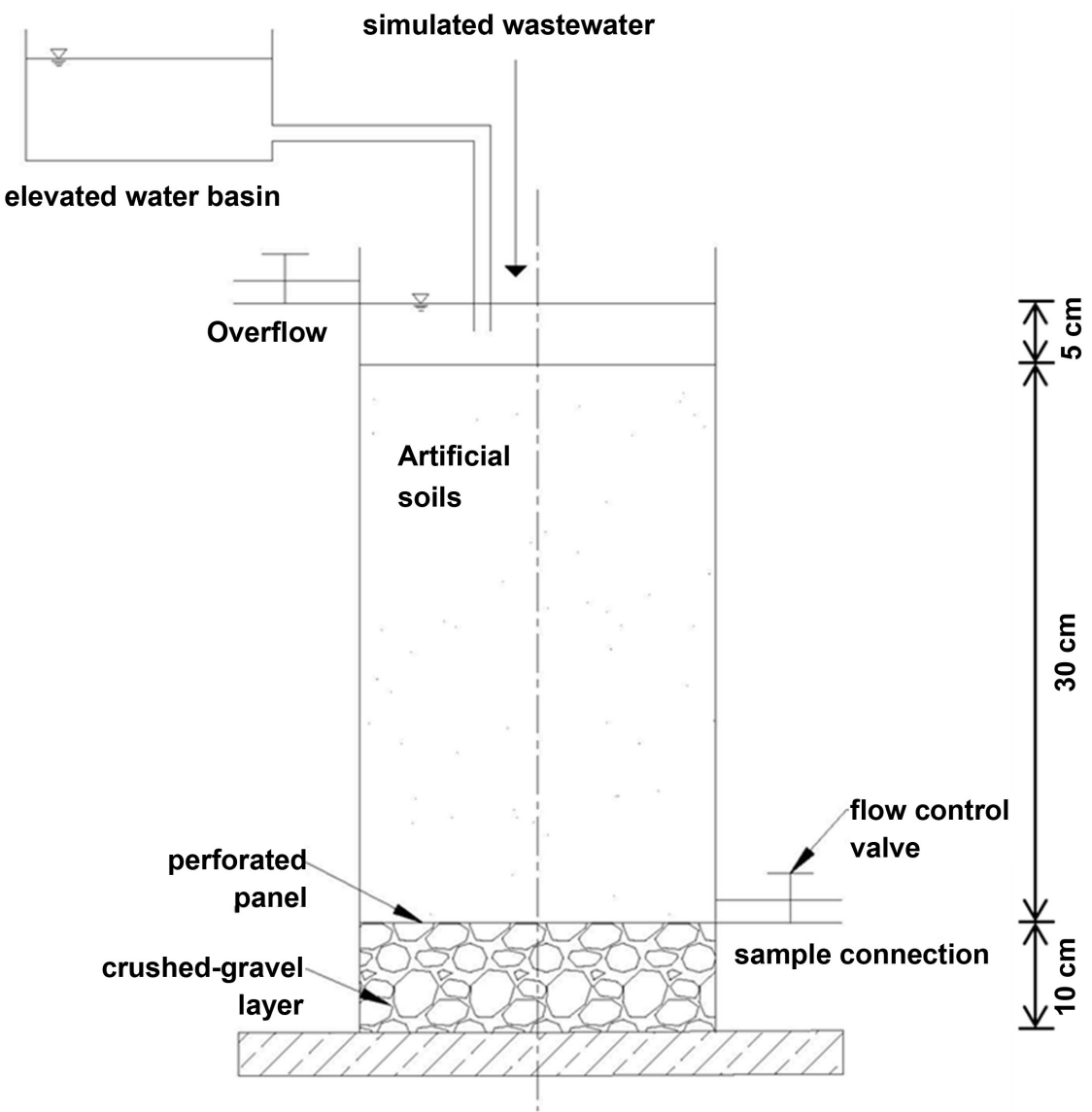

Figure 1. Reactor of artificial rapid infiltration system.

was carried out in indoor conditions for $35 \mathrm{~d}$. The room temperature ranged from $20^{\circ} \mathrm{C}$ to $23^{\circ} \mathrm{C}$ while the water temperature ranges from $21^{\circ} \mathrm{C}$ to $24^{\circ} \mathrm{C}$. The permeability and non-uniformity coefficient were firstly determined to test the specific requirements by artificial rapid infiltration system. Then the synthetic wastewater (mentioned in Table 1) was filtrated from the reactors and the concentrations of selected pollutants in effluents were analyzed to disclose the per- 
formance of artificial rapid infiltration system on the reduction of non-point source pollution by runoffs.

\subsection{Analytic Methods}

The determinations of COD, TN, TP, $\mathrm{NH}_{4}^{+}-\mathrm{N}$ and SS were performed in accordance with standard methods (APHA, 1998). The measurement of permeability coefficient of artificial soil is according to Darcy's law (Equation (1)) (Huang, 2005).

$$
Q=\frac{k A\left(h_{1}-h_{2}\right)}{L}
$$

where $k$ is the permeability coefficient; $A$ is the tested area.

The non-uniformity coefficient of artificial soils was obtained by screening test. $300 \mathrm{~g}$ of mixture were firstly taken and dried in a constant temperature box at $105^{\circ} \mathrm{C}$. Then $100 \mathrm{~g}$ of them was weighed for screening tests with a series of screens of $2.00 \mathrm{~mm}$ (10 meshes), $1.43 \mathrm{~mm}$ (14 meshes), $1.00 \mathrm{~mm}$ (18 meshes), $0.45 \mathrm{~mm}$ (40 meshes), $0.10 \mathrm{~mm}$ (150 meshes) and $0.063 \mathrm{~mm}$ ( 250 meshes). The non-uniformity coefficient was calculated based on the grading distribution curve: $K_{80}=\mathrm{d}_{80} / \mathrm{d}_{10}$. The $\mathrm{d}_{80}$ and $\mathrm{d}_{10}$ represents the pore sized of screens that allow $80 \%$ and $10 \%$ amounts of particles to filtrate.

\section{Results and Discussion}

\subsection{Permeability and Non-Uniformity with Different Artificial Soil Compositions}

The permeability is one of the most significant features in evaluating the artificial rapid infiltration system. The basic requirement for the permeability coefficient $(K)$ of an effective rapid soil infiltration system should be no less than $0.025 \mathrm{~cm} / \mathrm{min}$ (Huang, 2005). The permeability coefficient of natural soils in Suzhou was only $2.17 \times 10^{-4} \mathrm{~cm} / \mathrm{min}$ which was far below the required limits and thus it was suitable for the construction of rapid infiltration system directly. However, the permeability coefficient was remarkably increased due to the addition of coarse sand and zeolite and it was highly correlated with the mixing ratio. As shown in Table 3, the reactors with high addition of coarse sand contributed to the permeability most (Reactors $1-4 \#$ ). However, the sand was rich of inorganics which would affect the soil fertility and then the abundances of active microorganisms. The balance of permeability and soil fertility should be maintained. Considering these, the ratio of natural soil and sand should be set as 1:2 to $1: 1$ with proper addition of zeolite. Particularly, the permeability coefficient in reactor 13\# with the mixture of 1:1:0.15 was up to $0.1660 \mathrm{~cm} / \mathrm{min}$ which far exceeded the requirement of $0.025 \mathrm{~cm} / \mathrm{min}$.

Besides, the particle gradation level of artificial soils was also important to the final application which could be reflected by the non-uniformity coefficient $K_{80}$. The higher $K_{80}$ indicated the inhomogeneous distribution of mixture which was disadvantageous to the performance of percolation. 
Table 3. The permeability and non-uniformity coefficient in different reactors.

\begin{tabular}{cccccc}
\hline Reactor & $K(\mathrm{~cm} / \mathrm{min})$ & $K_{80}$ & Reactor & $K(\mathrm{~cm} / \mathrm{min})$ & $K_{80}$ \\
\hline $1 \#$ & 0.1409 & 7.55 & $9 \#$ & 0.0126 & 7.76 \\
$2 \#$ & 0.0966 & 7.64 & $10 \#$ & 0.0832 & 7.42 \\
$3 \#$ & 0.1317 & 7.57 & $11 \#$ & 0.0297 & 7.67 \\
$4 \#$ & 0.3864 & 7.38 & $12 \#$ & 0.0208 & 7.86 \\
$5 \#$ & 0.0198 & 7.60 & $13 \#$ & 0.1660 & 7.32 \\
$6 \#$ & 0.0081 & 7.73 & $14 \#$ & 0.0594 & 7.50 \\
$7 \#$ & 0.0067 & 7.92 & $15 \#$ & 0.0014 & 8.36 \\
$8 \#$ & 0.0124 & 7.86 & $16 \#$ & 0.0011 & 8.12 \\
\hline
\end{tabular}

Further analysis showed that the permeability coefficient increases with the decrease of the non-uniformity coefficient (as shown in Figure 2). The permeability coefficient was negatively correlated with the non-uniformity coefficient which could be expressed as the following equation.

$$
y=7.1668 x^{-0.0191} \quad R^{2}=0.8375
$$

The above results indicated that the particle gradation was one of the main factors affecting the permeability coefficient of artificial soil. By optimizing the mixing ratio of three different materials, the grading distribution level as well as permeability coefficient could be improved, which could stimulate the hydraulic loads of artificial soil rapid infiltration system for the reduction of non-point source pollution in urban areas.

\subsection{Performance of Artificial Rapid Infiltration Systems on the Pollutants Removal}

The removal efficiencies of various pollutants were shown in Figure 3. It can be seen that the removal efficiency of $\mathrm{NH}_{4}^{+}-\mathrm{N}$ could reach above $60 \%$ in all artificial soil columns (Figure 3(A)). Correspondingly, the TN removal was above $45 \%$ (Figure $3(B)$ ). The reason may be mainly attributed to the presence of zeolites which has been reported to have a strong adsorption effect on ammonia nitrogen (Rožlć et al., 2000). The dynamic adsorption tests also showed that the adsorptive ability of $\mathrm{NH}_{4}^{+}-\mathrm{N}$ was improved by $1.15-10.92 \mathrm{mg} / \mathrm{L}$ and the effective adsorption time was increased by $50 \%$ in the artificial soil with $5 \%$ zeolite addition.

However, the removal of COD and TP varied greatly in the reactors with different artificial soil proportions. As shown in Figure 3(C), the COD removal efficiency in reactors 1 - 4\# was all less that $15 \%$. It was mainly caused by the large permeability coefficient of artificial soil in reactors 1 - 4\#. In the artificial rapid infiltration system, the removal of organics could be accomplished through mechanical filtration, adsorption and biological oxidation of microorganisms. The microbial degradation was considered as the main mechanism for organics removal. However, the organic matters must be first hydrolyzed before the microbial 


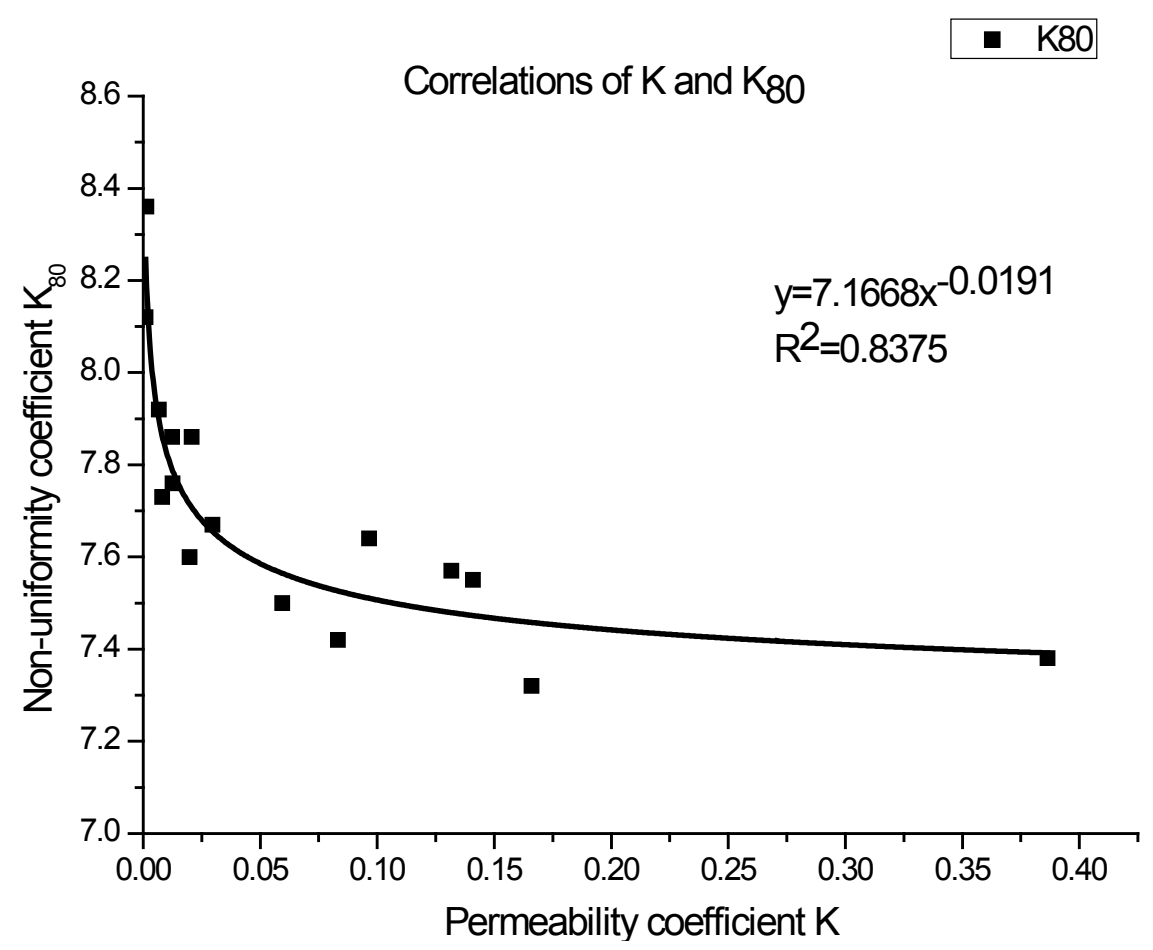

Figure 2. Correlations of permeability and non-uniformity coefficient.

absorption and utilization which required sufficient time. In the present study, the hydraulic retention time was short which was below $6 \mathrm{~h}$ considering the height of columns tested. Therefore, mechanical filtration and adsorption may become the main mechanism for the removal of organics removal in a short time. The treating performances in other artificial soil columns were all significantly higher than that of reactors 1 - 4\#.

As to the TP removal, high removal efficiency was obtained in the reactors of $1 \#$ and $13 \#$, which was respectively $78.8 \%$ and $74.1 \%$. However, the lowest removal efficiency was observed in reactor $8 \#$ which was only $6.4 \%$. The removal of TP in soils could be achieved via plants intake, soil adsorption, chemical precipitation and microbial accumulation (APHA, 1998). In this study, the plants intake could be excluded. Also, the biological accumulation of phosphorus by microorganisms was limited considering the short hydraulic retention time. The TP removal was also mainly attributed to the soils adsorption and chemical precipitation. However, they were also affected by numerous factors, such as the ions exchange capacity, $\mathrm{pH}$, hydraulic loads and retention time in the systems (Reneau et al., 1989; Zhu et al., 2017; Semerci et al., 2010). Due to the different composition of artificial soils that resulted in the variations of physiochemical characteristics, the adsorption and chemical precipitation of phosphorus were affected in different degrees.

Considering the cumulative performance of pollutants removal in different reactors (as shown in Figure 3(E)), the 9\#, 13\# and 14\# reactors showed promising application as artificial rapid infiltration system, particularly reactor 13\# 

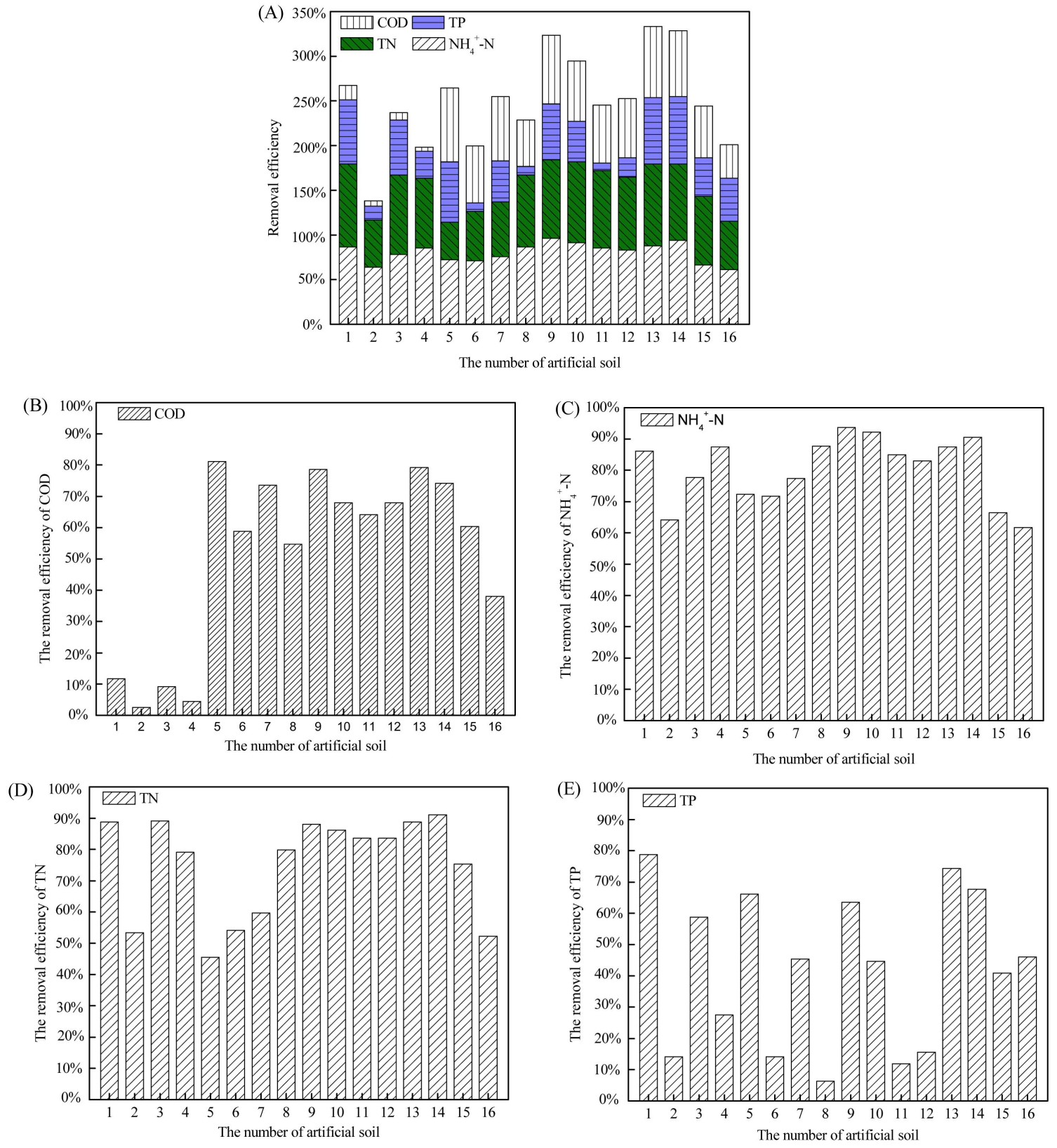

Figure 3. Removal rates of various pollutants with different artificial soils.

with a removal efficiency of $74 \%$ for all pollutants. Moreover, the permeability coefficient in reactor 13\# met the requirement for the rapid infiltration system (not the case in 9\# reactor) and the cost was also relatively economic considering the low zeolite consumption (5\% versus the $10 \%$ in $14 \#$ reactor).

\section{Conclusion}

The natural soil, coarse sand and zeolite were suitable for the components of artificial rapid infiltration systems with optimized mixing ratios. With the ratio of 1:1:0.05 for natural soil, coarse sand and zeolite, the permeability coefficient of artificial soils was improved to $0.166 \mathrm{~cm} / \mathrm{min}$ which met the requirement of ar- 
tificial soil rapid infiltration systems. The removal efficiency of COD, $\mathrm{NH}_{4}^{+}-\mathrm{N}$, TN and TP in synthetic rain runoffs was respectively $79.2 \%, 88.1 \%, 88.8 \%$ and $74.1 \%$ in the artificial rapid infiltration systems, which exhibited the feasibility and effectiveness on the reduction of urban non-point pollution.

\section{Acknowledgements}

This work is financially supported by the water conservancy science technology project of Jiangsu province (2016040, 2017047), Special Funds for the Science and Technology Program of Public Wellbeing of Ningbo (2017C50002), Research Institute funds of Ningbo (2017A8002).

\section{Conflicts of Interest}

The authors declare no conflicts of interest regarding the publication of this paper.

\section{References}

Aljerf, L. (2018). High-Efficiency Extraction of Bromocresol Purple Dye and Heavy Metals as Chromium from Industrial Effluent by Adsorption onto a Modified Surface of Zeolite: Kinetics and Equilibrium Study. Journal of Environmental Management, 225, 120-132. https://doi.org/10.1016/j.jenvman.2018.07.048

APHA (1998). Standard Methods for the Examination of Water and Wastewater (20th ed.). Washington DC: American Public Health Association.

Boostani, H. R., Hardie, A. G., Najafi-Ghiri, M., \& Khalili, D. (2017). Investigation of Cadmium Immobilization in a Contaminated Calcareous Soil as Influenced by Biochars and Natural Zeolite Application. International Journal of Environmental Science \& Technology, 15, 2433-2446.

Coppola, A., Dragonetti, G., Comegna, A., Zdruli, P., Lamaddalena, N., Pace, S., \& Simone, L. D. (2014). Mapping Solute Deep Percolation Fluxes at Regional Scale by Integrating a Process-Based Vadose Zone Model in a Monte Carlo Approach. Soil Science \& Plant Nutrition, 60, 71-91. https://doi.org/10.1080/00380768.2013.855615

Ding, C. C., \& Liu, J. (2011). Discussion on Urban Non-Point Source Pollution and Control Technologies in China. China Population, Resources and Environment, 21, 86-89.

Feng, C., Cai, Z., Yin, X., Nan, M. I., \& Cai, Z. (2016). Effect of Plants on Phosphorus Control and Transformation in Soil Infiltration System in Rainwater Runoff. Environmental Pollution \& Control, 3, 25-33.

Huang, J. J., \& Xiang, W. (2014). Investigation of Point Source and Non-Point Source Pollution for Panjiakou Reservoir in North China by Modelling Approach. Water Quality Research Journal of Canada, 50, 167-181. https://doi.org/10.2166/wqric.2014.019

Huang, J. X. (2010). Origin Analysis on Non-Point Source Pollution and Countermeasures of the Chaobai River in Shunyi New Town. Beijing Water, 4, 4-7.

Huang, W. (2005). Study on the Artificial Soil Rapid Infiltration System for the Reduciton of Pollution Load in Urban Non-Point Source. Nanjing: Hohai University.

Jing, H.W., Hua, L., \& Guo, J. (2013). Non-Point Source Pollution Monitoring and Its Loads Estimation Study on Surface Water Environment in Beijing. Environmental Monitoring in China, 28, 106-111. 
Lai, X., Liao, K., Feng, H., \& Zhu, Q. (2016). Responses of Soil Water Percolation to Dynamic Interactions among Rainfall, Antecedent Moisture and Season in a Forest Site. Journal of Hydrology, 540, 565-573. https://doi.org/10.1016/j.jhydrol.2016.06.038

Li, C., Zheng, X., Zhao, F., Wang, X., Cai, Y., \& Zhang, N. (2017). Effects of Urban Non-Point Source Pollution from Baoding City on Baiyangdian Lake, China. Water, 9, 249. https://doi.org/10.3390/w9040249

Li, D., Zheng, B., Liu, Y., Chu, Z., He, Y., \& Huang, M. (2018). Use of Multiple water Surface Flow Constructed Wetlands for Non-Point Source Water Pollution Control. Applied Microbiology \& Biotechnology, 102, 5355-5368. https://doi.org/10.1007/s00253-018-9011-8

Li, T., Lin, L. F., \& Li, H. (2006). Characteristics and Control of Urban Runoff Pollution in Shanghai. Environmental Pollution \& Control, 28, 868-871.

Liu, W., Qiao, C., Yang, S., Bai, W., \& Liu, L. (2018). Microbial Carbon Use Efficiency and Priming Effect Regulate Soil Carbon Storage under Nitrogen Deposition by Slowing Soil Organic Matter decomposition. Geoderma, 332, 37-44.

https://doi.org/10.1016/j.geoderma.2018.07.008

Qin, P., Lei, K., Soon-Thiam, K., \& Qiao, F. (2016). Discussion on Characteristics and Model Application of Urban Nonpoint Source Pollution in China. Journal of Environmental Engineering Technology, 6, 397-406.

Reneau, R. B., Hagedorn, C., \& Degen, M. J. (1989). Fate and Transport of Biological and Inorganic Contaminants from On-Site Disposal of Domestic Wastewater. Journal of Environmental Quality, 18, 135-144. https://doi.org/10.2134/jeq1989.00472425001800020001x

Roz`ć, M., Cerjanstefanović, Š., Kurajica, S., Vančina, V., \& Hodzૉć, E. (2000). Ammoniacal Nitrogen Removal from Water by Treatment with Clays and Zeolites. Water Research, 34, 3675-3681. https://doi.org/10.1016/S0043-1354(00)00113-5

Semerci, N., Bakici, N., \& Kocamemi, B. A. (2010). Effects of Nitrite, Oxygen and Initial $\mathrm{pH}$ on Biological Phosphorus Removal in a Post-Denitrification System. Journal of Biotechnology, 150, 292-292. https://doi.org/10.1016/j.jbiotec.2010.09.239

Wang, M., Xie, R. Z., Chen, Y., Pu, X. Q., Jiang, W. J., \& Yao, L. (2018). A Novel Mesoporous Zeolite-Activated Carbon Composite as an Effective Adsorbent for Removal of Ammonia-Nitrogen and Methylene Blue from Aqueous Solution. Bioresource Technology, 268, 726-732. https://doi.org/10.1016/j.biortech.2018.08.037

Wang, Z. S., \& Wang, C. D. (2011). Review on Main Technology Development about Constructed Rapid Infiltration System in China. Journal of Sichuan University of Science \& Engineering, 24, 493-496.

Xue, Y., Zhang, X., Xudong, L. I., \& Guanghe, L. I. (2003). Storm-Water Pollution Control Using Zeolite Nitrogen Absorption System. Journal of Tsinghua University, 43, 854-857.

Zhu, C., Wang, Q., Pang, W., Wang, Z., Cao, J., Hu, W., Tang, J., Huang, J., \& Wu, Z. (2017). Mechanisms of Phosphorus Removal from Wastewater by Ion Exchange Resin. Desalination \& Water Treatment, 79, 347-355.

https://doi.org/10.5004/dwt.2017.20890

Zhuang, Y., Hong, S., Zhan, F. B., \& Zhang, L. (2015). Influencing Factor Analysis of Phosphorus Loads from Non-Point Source: A Case Study in Central China. Environmental Monitoring \& Assessment, 187, 718. https://doi.org/10.1007/s10661-015-4946-z 